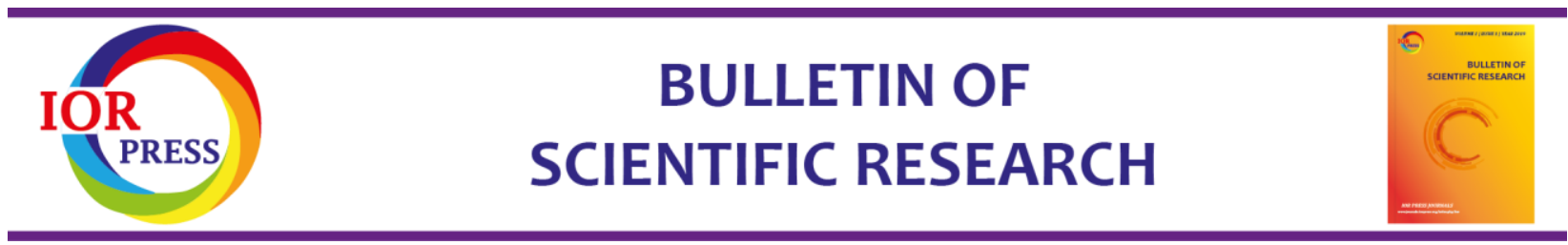

\title{
Design and Analsyis of 31-Level Asymmetric Cascaded H-Bridge Multilevel Inverter with Reduced Number of Switches
}

\section{A. Manoranjan a, ${ }^{*}$, C. Christober Asir Rajan a}

a Department of Electrical and Electronics Engineering, Pondicherry Engineering College, Puducherry, Tamil Nadu, India.

*Corresponding Author: vjcmano@gmail.comDOI: https://doi.org/10.34256/bsr2023

Received: 02-05-2020

Accepted: 23-09-2020

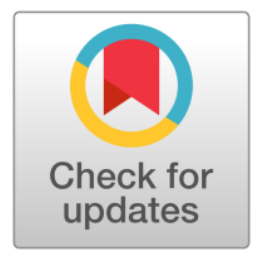

\begin{abstract}
A new multilevel inverter with less no of power switches is proposed. This is based on cascaded H-bridge topology. The design and analysis of 31level reduced switch inverter with different modes of operation are presented in this paper. The proposed inverter is asymmetric in nature and it uses unequal DC voltage sources. PD-PWM modulation technique has been used here to get proper switching. The proposed idea has been validated through simulation and the received results provides better efficiency, less low order harmonics and less switching losses.
\end{abstract}

Keywords: Multilevel Inverter (MLI), Phase Disposition Pulse Width Modulation (PD-PWM), Cascaded H-bridge, Total Harmonic Distortion (THD).

\section{Introduction}

Multilevel inverter is a new domain of power converters used extensively in high and medium power applications such as integration of renewable energy resources, FACTS devices and so on [1-3]. The obtained output voltage waveform is nearly sinusoidal. In power electronic applications multilevel inverters are becoming popular as they have the good ability to meet the more demand of power rating and power quality associated with reduced harmonic distortion and lower electromagnetic interference. Multilevel inverter has the ability to operate with both fundamental and high switching frequency [1,5-9]. Basically, there are three different topologies employed for Multilevel inverter: Neutral point clamp MLI (NPC), Flying capacitor MLI (FC) and Cascaded H-bridge MLI (CHB) $[1,10]$. In this the Cascaded $\mathrm{H}$-bridge topology has gained a lot of interest because of its simplicity and modularity with the limitation of separate DC sources for each module when compared with other topologies such as NPC and FC [1].

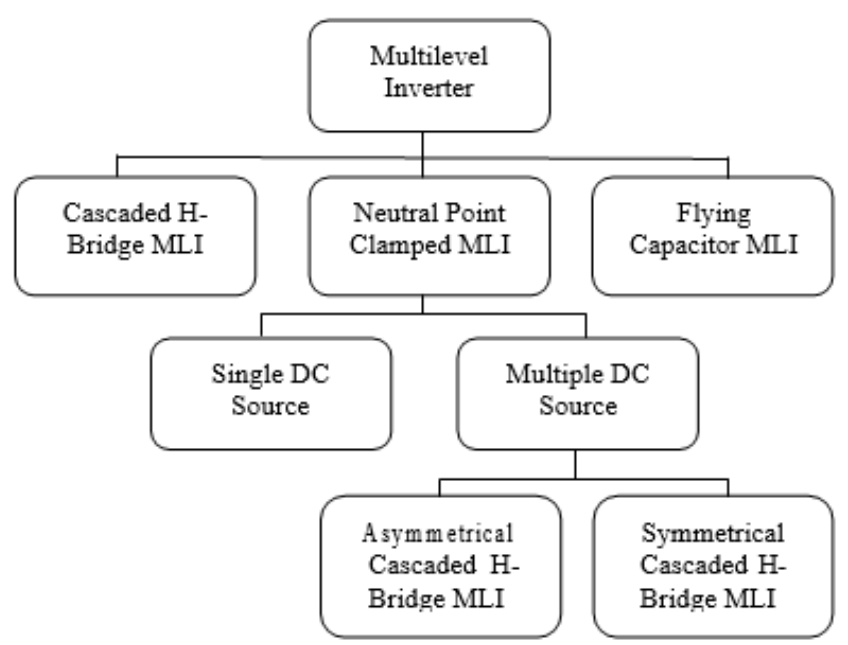

Fig 1. Flow Chart of MLI Topologies.

On the basis of magnitude of DC voltages, CHB topology fall into two categories: Symmetric CHB and Assymetric CHB. The asymmetric topology utilizes a smaller number of switches, DC sources and diodes for same 
voltage levels as compared to symmetric topology [1]. The proposed MLI topology has more advantages than the existing topologies as the number of switching devices and total harmonic distortion are reduced.

In asymmetric multilevel inverter, DC source magnitudes are unequal and it is designed as to maintain a ratio of 1:2:4:8 [1116]. A $2 \mathrm{Khz}$ multiple carrier signal is used to develop phase disposition pulse width modulation (PD-PWM). In this paper, level shifted PWM topologies with reduced no of switches which uses separate DC sources has been designed. The no of switches and no of levels are represented as follows

$$
\text { N_Level }=2(n+1)-1
$$

N_MOSFET $=n+4$ where $n-$ no of DC sources.

The DC source magnitudes are designed with binary form of voltage such as $3 \mathrm{~V}, 6 \mathrm{~V}, 12 \mathrm{~V}$ and $24 \mathrm{~V}$.

\section{Proposed System}

This section presents a detailed description of the proposed system which has additional features with added flexibility to that of the existing systems.

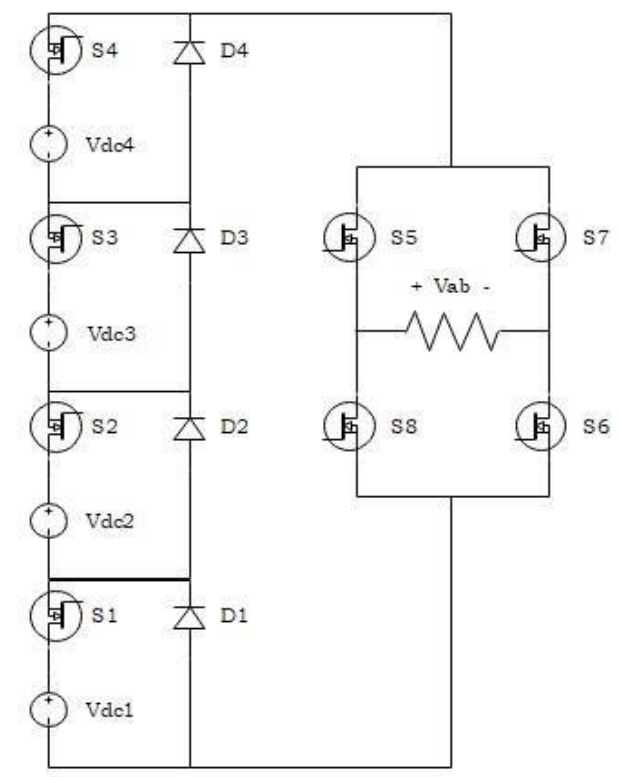

Fig 2. Block Diagram of Proposed System.
It is implemented with a set of switch, diode and DC source at the input side of the circuit which produces higher output voltage level.

\section{Switching Modes of Operation}

Based on the gating signals, the four MOSFET switches in different times to create 31 different voltage levels which are shown in this section.

Table 1. Switching Order of MOSFET's Based on Gate Signals

\begin{tabular}{|c|c|c|c|c|c|c|c|c|}
\hline Vo & S1 & S2 & S3 & S4 & S5 & S6 & S7 & S8 \\
\hline Vdc & 1 & 1 & 1 & 1 & 1 & 1 & 0 & 0 \\
\hline $14 \mathrm{Vdc} / 15$ & 0 & 1 & 1 & 1 & 1 & 1 & 0 & 0 \\
\hline $13 \mathrm{Vdc} / 15$ & 1 & 0 & 1 & 1 & 1 & 1 & 0 & 0 \\
\hline $12 \mathrm{Vdc} / 15$ & 0 & 0 & 1 & 1 & 1 & 1 & 0 & 0 \\
\hline $11 \mathrm{Vdc} / 15$ & 1 & 1 & 0 & 1 & 1 & 1 & 0 & 0 \\
\hline $10 \mathrm{Vdc} / 15$ & 0 & 1 & 0 & 1 & 1 & 1 & 0 & 0 \\
\hline $9 \mathrm{Vdc} / 15$ & 1 & 0 & 0 & 1 & 1 & 1 & 0 & 0 \\
\hline $8 \mathrm{Vdc} / 15$ & 0 & 0 & 0 & 1 & 1 & 1 & 0 & 0 \\
\hline $7 \mathrm{Vdc} / 15$ & 1 & 1 & 1 & 0 & 1 & 1 & 0 & 0 \\
\hline $6 \mathrm{Vdc} / 15$ & 0 & 1 & 1 & 0 & 1 & 1 & 0 & 0 \\
\hline $5 \mathrm{Vdc} / 15$ & 1 & 0 & 1 & 0 & 1 & 1 & 0 & 0 \\
\hline $4 \mathrm{Vdc} / 15$ & 0 & 0 & 1 & 0 & 1 & 1 & 0 & 0 \\
\hline $3 \mathrm{Vdc} / 15$ & 1 & 1 & 0 & 0 & 1 & 1 & 0 & 0 \\
\hline $2 \mathrm{Vdc} / 15$ & 0 & 1 & 0 & 0 & 1 & 1 & 0 & 0 \\
\hline $\mathrm{Vdc} / 15$ & 1 & 0 & 0 & 0 & 1 & 1 & 0 & 0 \\
\hline 0 & 0 & 0 & 0 & 0 & 1 & 0 & 1 & 0 \\
\hline 0 & 0 & 0 & 0 & 0 & 0 & 1 & 0 & 1 \\
\hline$-\mathrm{Vdc} / 15$ & 1 & 0 & 0 & 0 & 0 & 0 & 1 & 1 \\
\hline$-2 \mathrm{Vdc} / 15$ & 0 & 1 & 0 & 0 & 0 & 0 & 1 & 1 \\
\hline$-3 \mathrm{Vdc} / 15$ & 1 & 1 & 0 & 0 & 0 & 0 & 1 & 1 \\
\hline$-4 \mathrm{Vdc} / 15$ & 0 & 0 & 1 & 0 & 0 & 0 & 1 & 1 \\
\hline$-5 \mathrm{Vdc} / 15$ & 1 & 0 & 1 & 0 & 0 & 0 & 1 & 1 \\
\hline$-6 \mathrm{Vdc} / 15$ & 0 & 1 & 1 & 0 & 0 & 0 & 1 & 1 \\
\hline$-7 \mathrm{Vdc} / 15$ & 1 & 1 & 1 & 0 & 0 & 0 & 1 & 1 \\
\hline$-8 \mathrm{Vdc} / 15$ & 0 & 0 & 0 & 1 & 0 & 0 & 1 & 1 \\
\hline$-9 \mathrm{Vdc} / 15$ & 1 & 0 & 0 & 1 & 0 & 0 & 1 & 1 \\
\hline$-10 \mathrm{Vdc} / 15$ & 0 & 1 & 0 & 1 & 0 & 0 & 1 & 1 \\
\hline$-11 \mathrm{Vdc} / 15$ & 1 & 1 & 0 & 1 & 0 & 0 & 1 & 1 \\
\hline$-12 \mathrm{Vdc} / 15$ & 0 & 0 & 1 & 1 & 0 & 0 & 1 & 1 \\
\hline$-13 \mathrm{Vdc} / 15$ & 1 & 0 & 1 & 1 & 0 & 0 & 1 & 1 \\
\hline$-14 \mathrm{Vdc} / 15$ & 0 & 1 & 1 & 1 & 0 & 0 & 1 & 1 \\
\hline$-\mathrm{Vdc}$ & 1 & 1 & 1 & 1 & 0 & 0 & 1 & 1 \\
\hline
\end{tabular}


Vol 2 Iss 2 Year 2020

Mode 1:

Switch S1, S2, S3, S4, S5 and S6 is ON, the voltage is maximum $+\mathrm{Vdc}$ across the load.

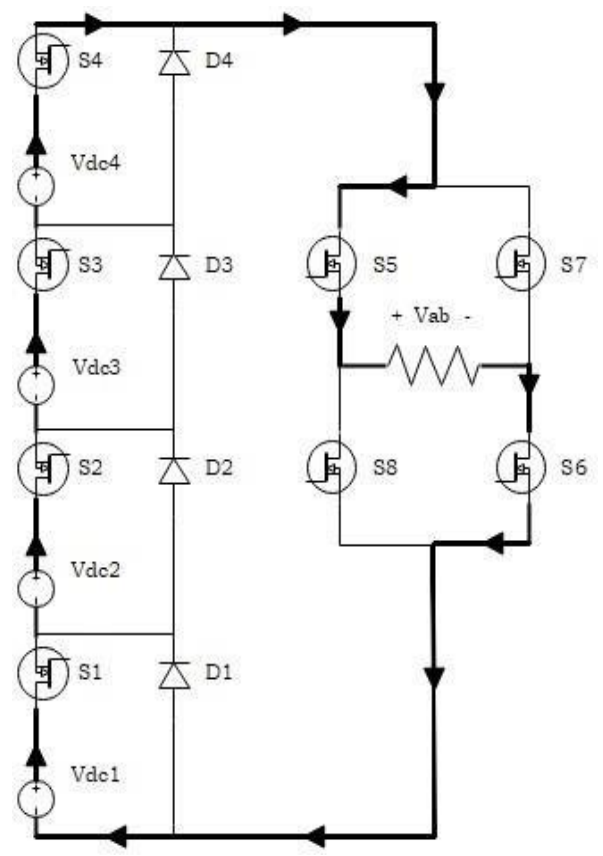

Fig 3. Mode 1

Mode 2:

Switch S2, S3, S4, S5 and S6 is ON, the voltage is $+14 \mathrm{Vdc} / 15$ across the load

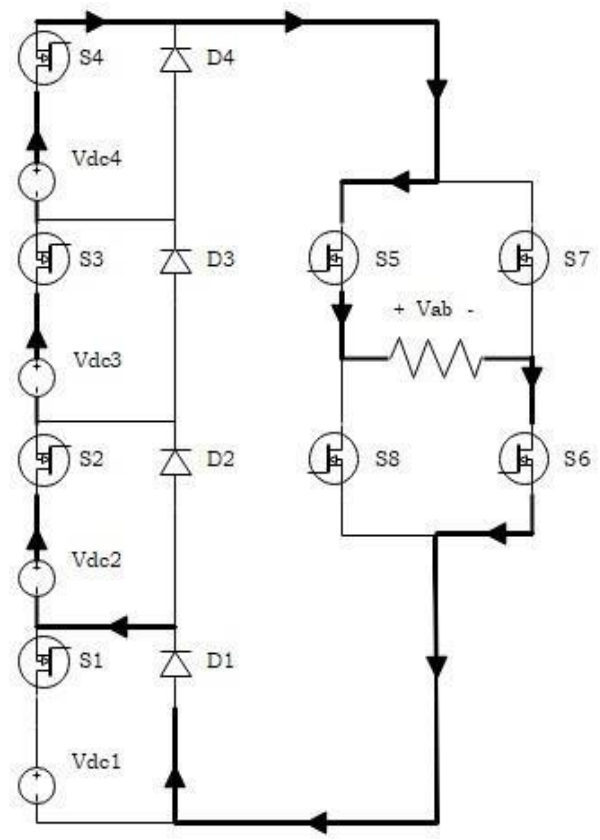

Fig 4. Mode 2
Mode 3:

Switch S1, S3, S4, S5 and S6 is ON, the voltage is $+13 \mathrm{Vdc} / 15$ across the load.

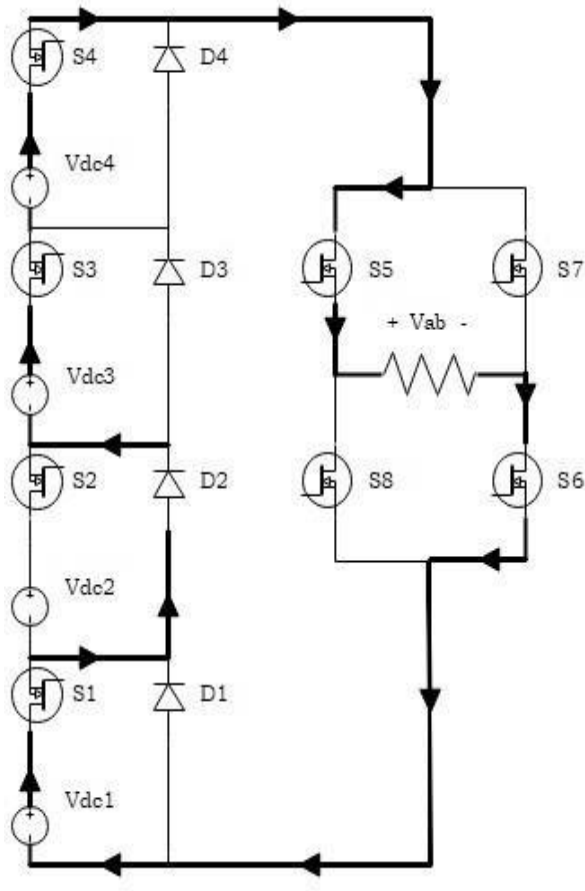

Fig 5. Mode 3

\section{Mode 4:}

Switch S3, S4, S5 and S6 is ON, the voltage is $+12 \mathrm{Vdc} / 15$ across the load.

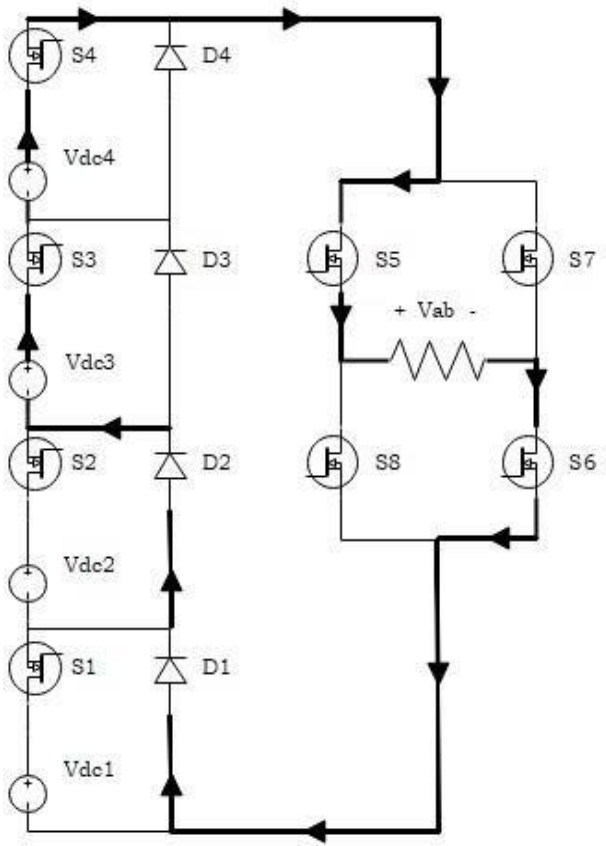

Fig 6. Mode 4 
Vol 2 Iss 2 Year 2020

Mode 5:

Switch S1, S2, S4, S5 and S6 is ON, the voltage is $+11 \mathrm{Vdc} / 15$ across the load.

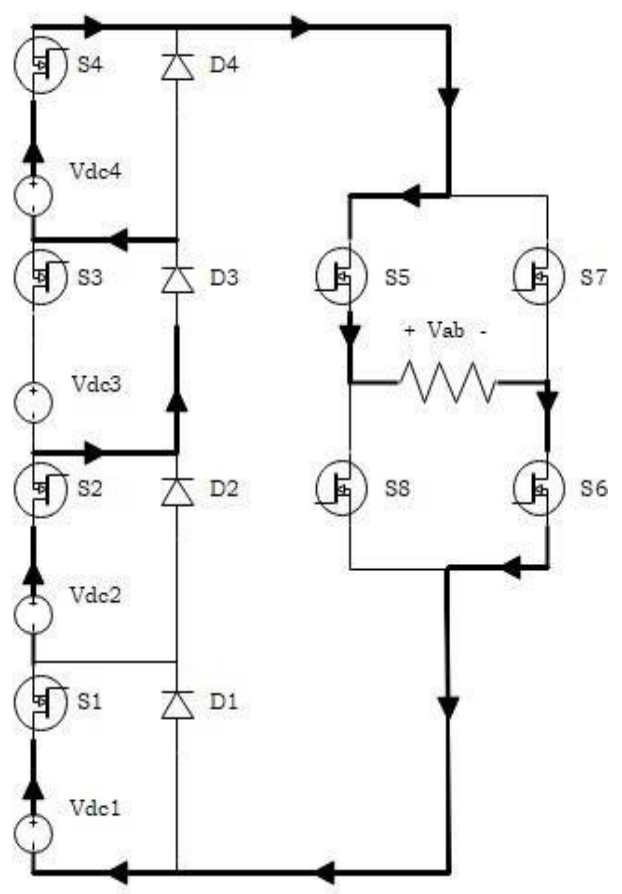

Fig 7. Mode 5

\section{Mode 6:}

Switch S2, S4, S5 and S6 is ON, the voltage is $+10 \mathrm{Vdc} / 15$ across the load.

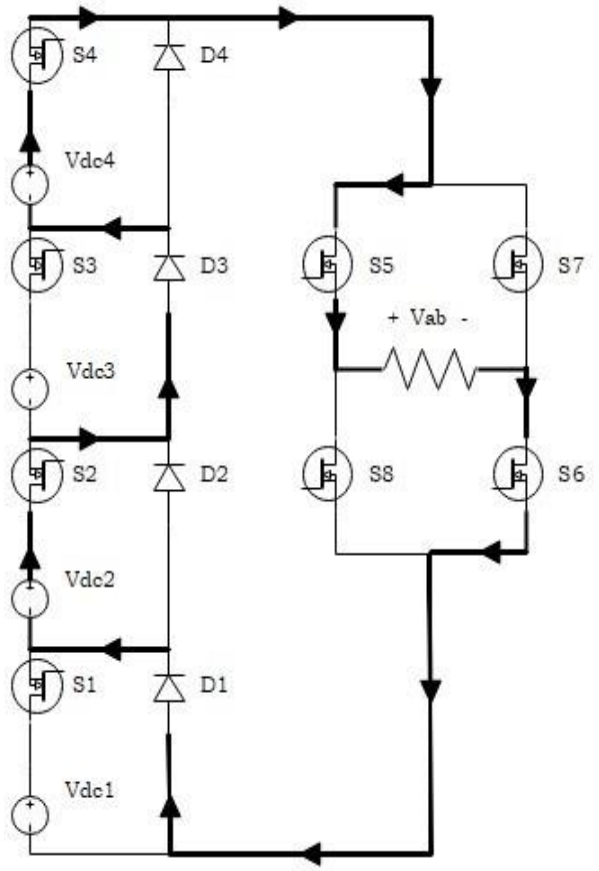

Fig 8. Mode 6
Mode 7:

Switch S1, S4, S5 and S6 is ON, the voltage is $+9 \mathrm{Vdc} / 15$ across the load.

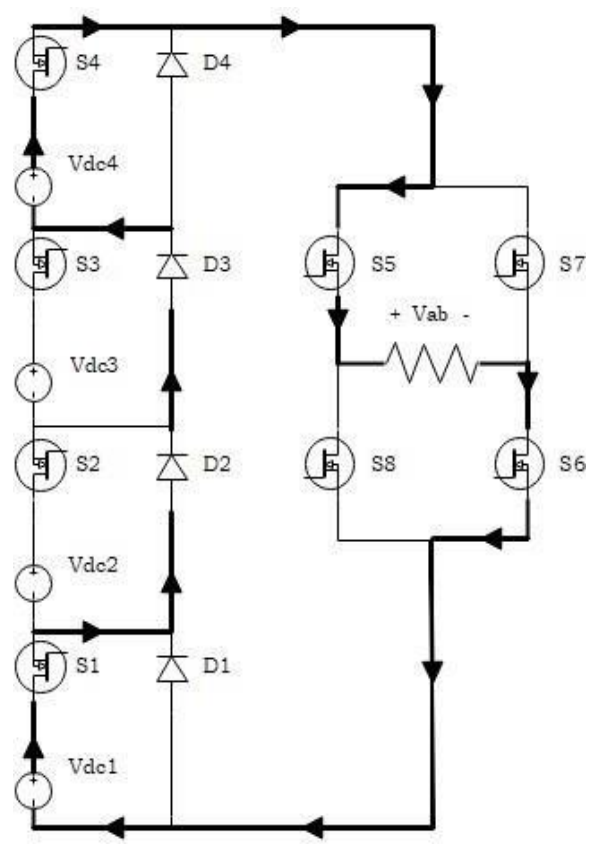

Fig 9. Mode 7

\section{Mode 8:}

Switch S4, S5 and S6 is ON, the voltage is $+8 \mathrm{Vdc} / 15$ across the load.

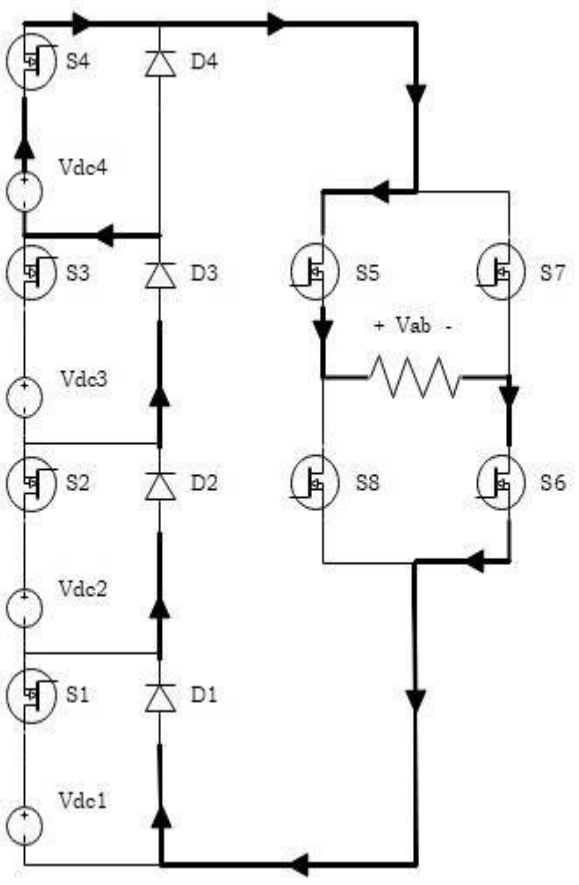

Fig 10. Mode 8 


\section{Mode 9:}

Switch S1, S2, S3, S5 and S6 is ON, the voltage is $+7 \mathrm{Vdc} / 15$ across the load.

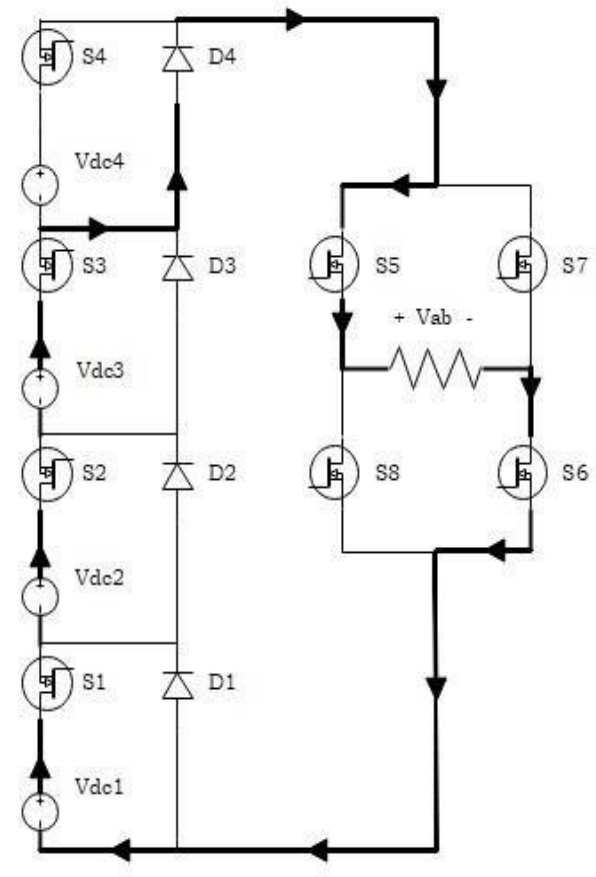

Fig 11. Mode 9

\section{Mode 10:}

Switch S2, S3, S5 and S6 is ON, the voltage is $+6 \mathrm{vdc} / 15$ across the load.

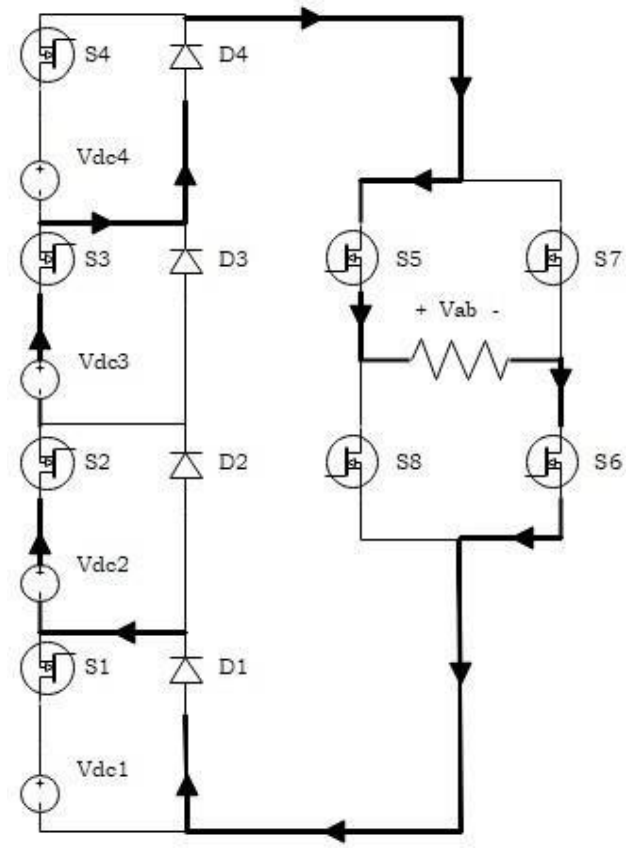

Fig 12. Mode 10

\section{Mode 11:}

Switch S1, S3, S5 and S6 is ON, the voltage is $+5 \mathrm{Vdc} / 15$ across the load.

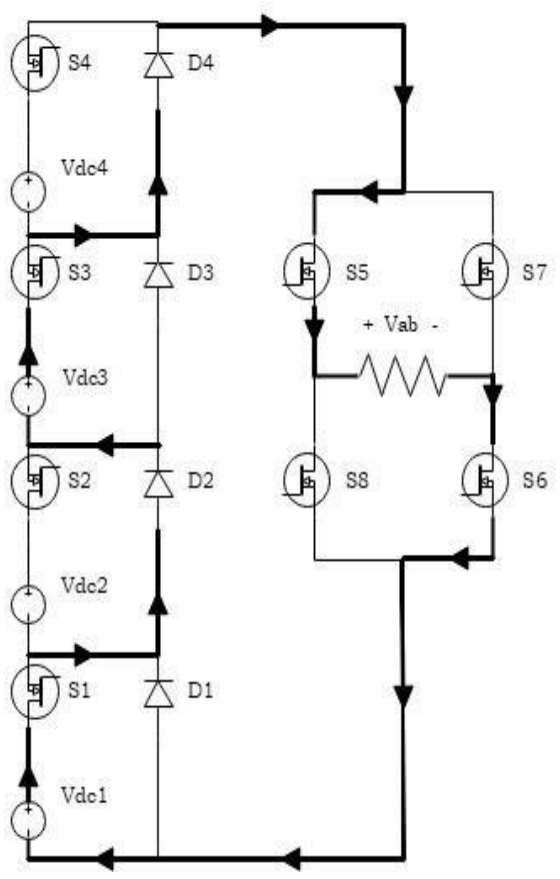

Fig 13. Mode 11

\section{Mode 12:}

Switch S3, S5 and S6 is ON, the voltage is $+4 \mathrm{Vdc} / 15$ across the load.

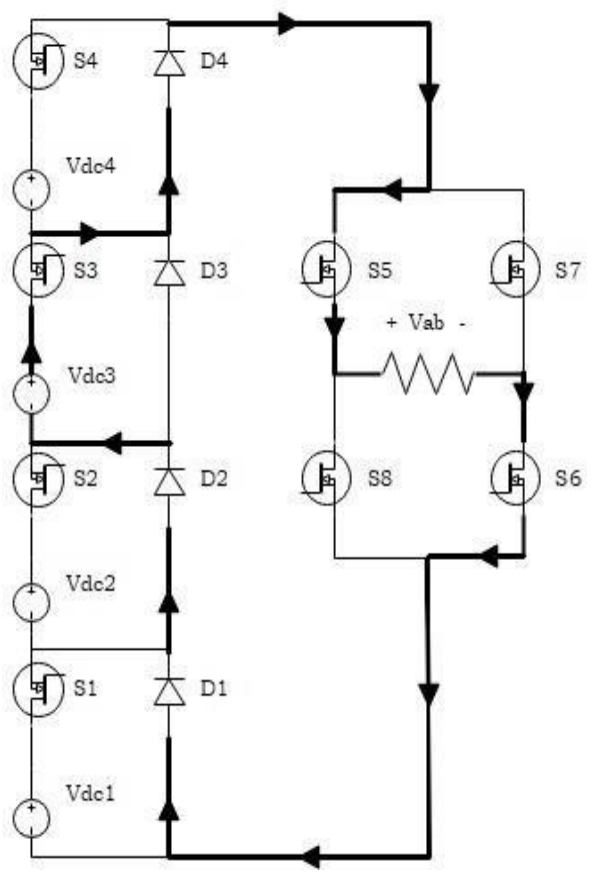

Fig14. Mode 12 
Vol 2 Iss 2 Year 2020

Mode 13:

Switch S1, S2, S5 and S6 is ON, the voltage is $+3 \mathrm{Vdc} / 15$ across the load.

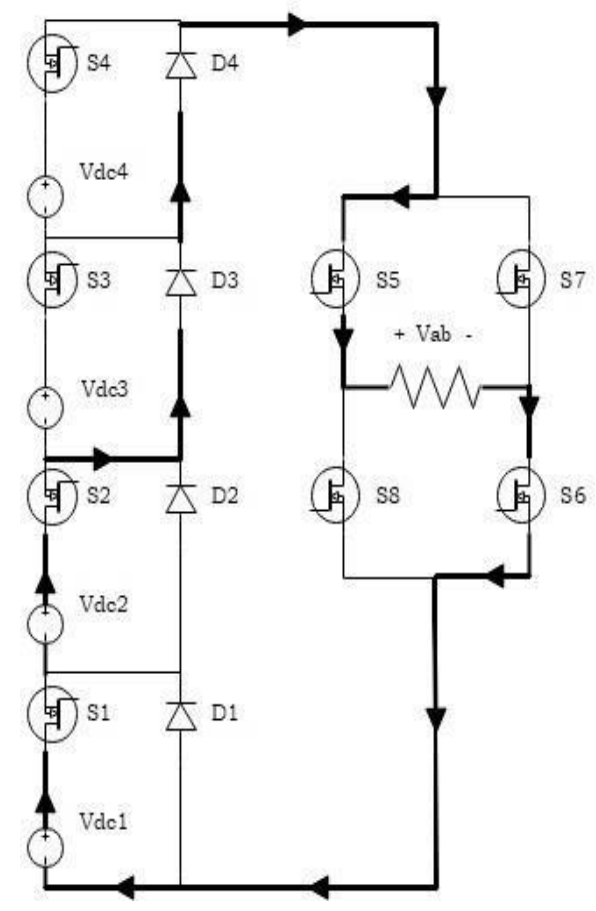

Fig15. Mode 13

\section{Mode 14:}

Switch S2, S5 and S6 is ON, the voltage is $+2 \mathrm{Vdc} / 15$ across the load.

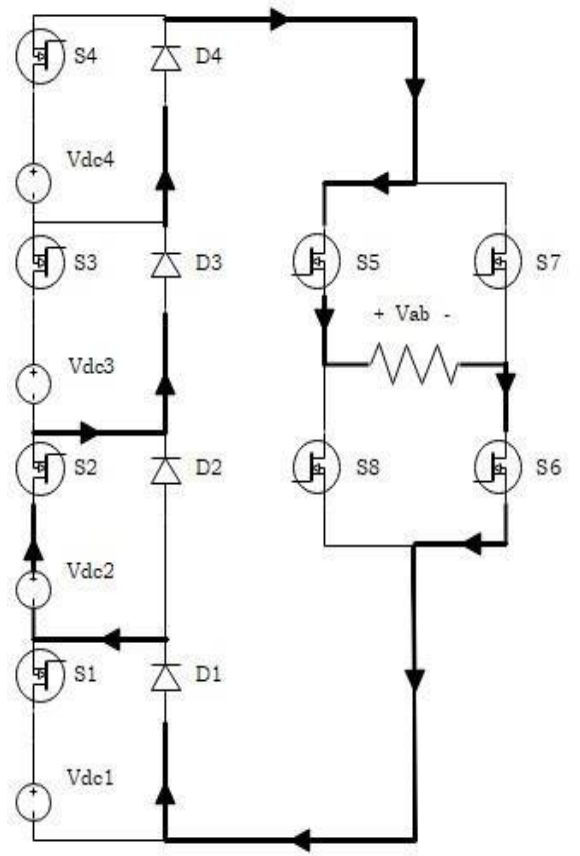

Fig 16. Mode 14
Mode 15:

Switch S1, S5 and S6 is ON, the voltage is $+\mathrm{Vdc} / 15$ across the load.

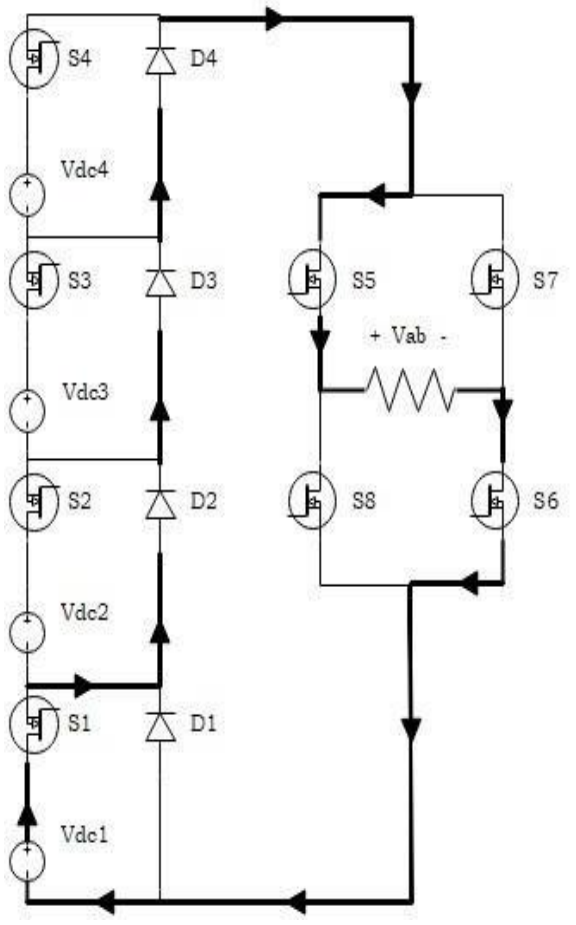

Fig 17. Mode 15

Mode 16a:

The zero-output voltage level is produced by turning ON switch S5 and S7.

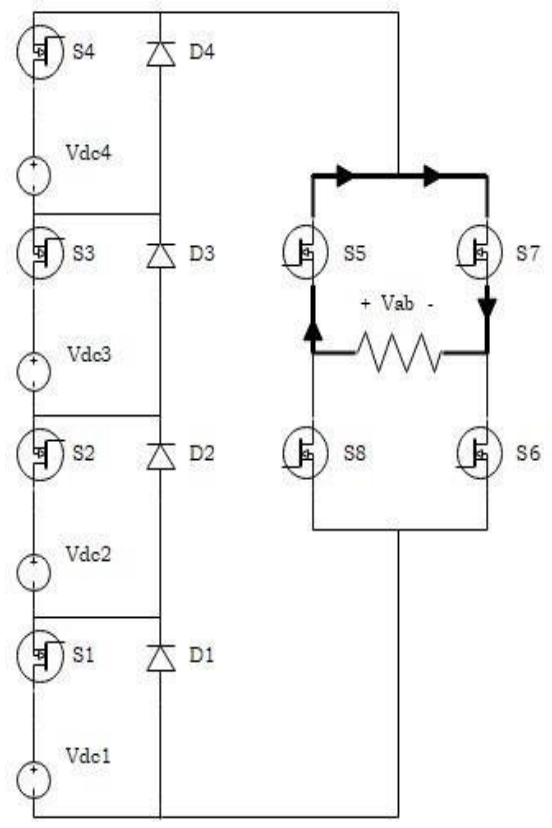

Fig 18. Mode 16a 
Vol 2 Iss 2 Year 2020

Mode 16b:

The zero-output voltage level is produced by turning ON switch S6 and S8.

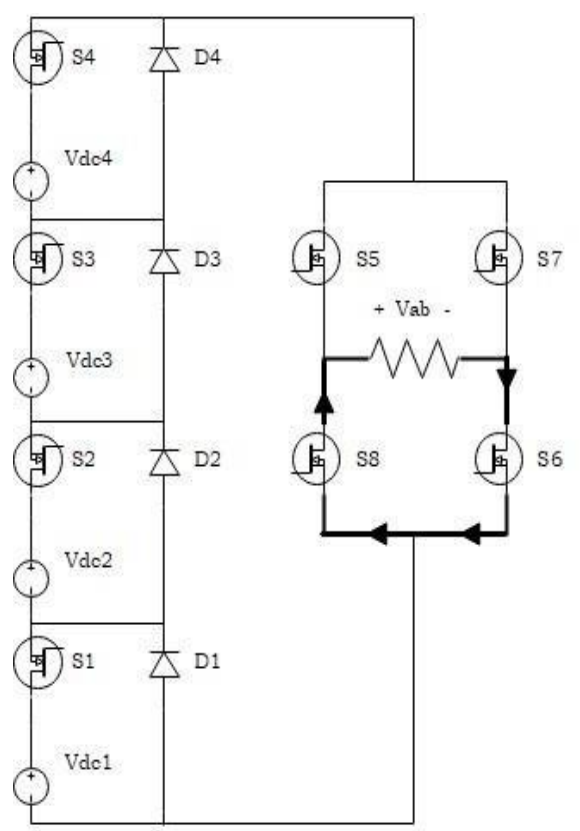

Fig 19. Mode 16b

\section{Mode 17:}

Switch S1, S7 and S8 is ON, the voltage is $-V d c / 15$ across the load.

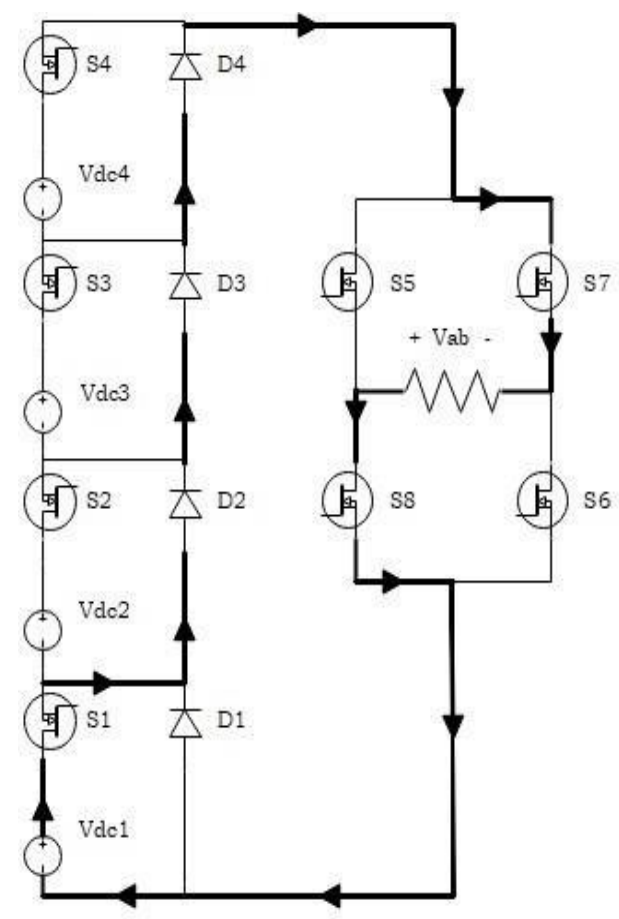

Fig 20. Mode 17
Mode 18:

Switch S2, S7 and S8 is ON, the voltage is $-2 \mathrm{Vdc} / 15$ across the load.

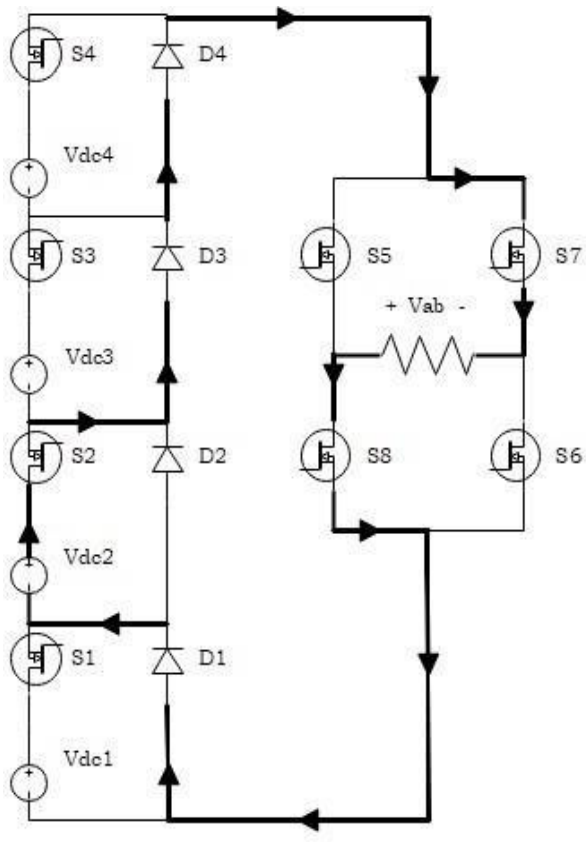

Fig 21. Mode 18

\section{Mode 19:}

Switch S1, S2, S7 and S8 is ON, the voltage is $-3 \mathrm{Vdc} / 15$ across the load.

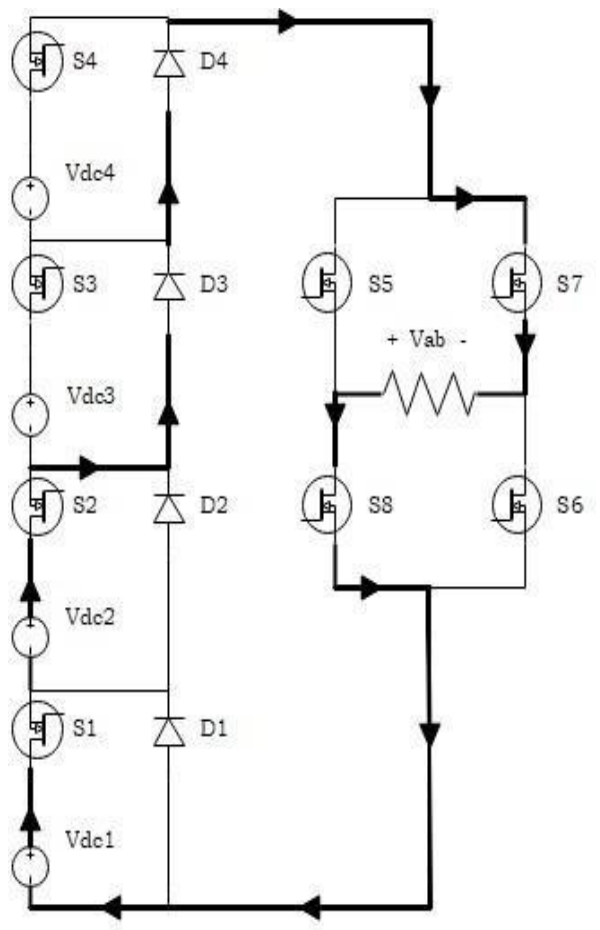

Fig 22. Mode 19 
Vol 2 Iss 2 Year 2020

Mode 20:

Switch S3, S7 and S8 is ON, the voltage is $-4 \mathrm{Vdc} / 15$ across the load.

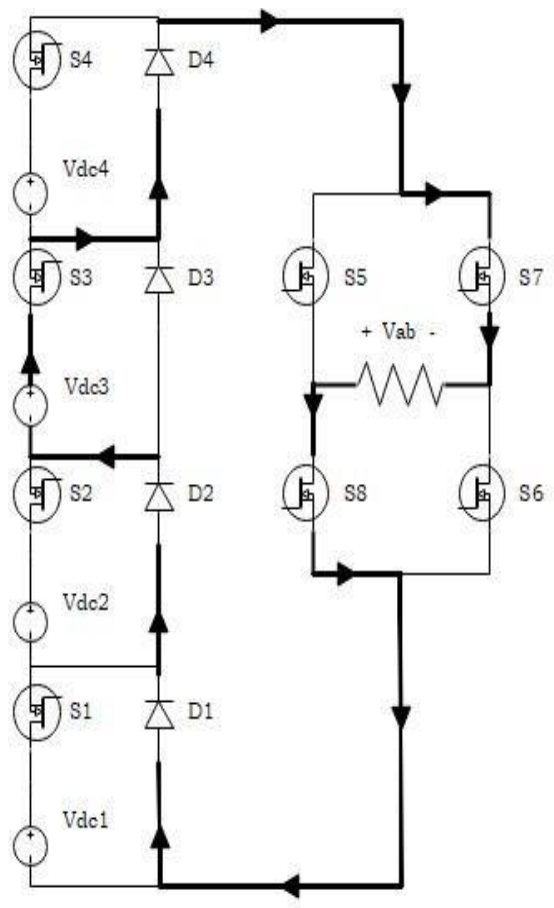

Fig 23. Mode 20

\section{Mode 21:}

Switch S1, S3, S7 and S8 is ON, the voltage is $-5 \mathrm{Vdc} / 15$ across the load.

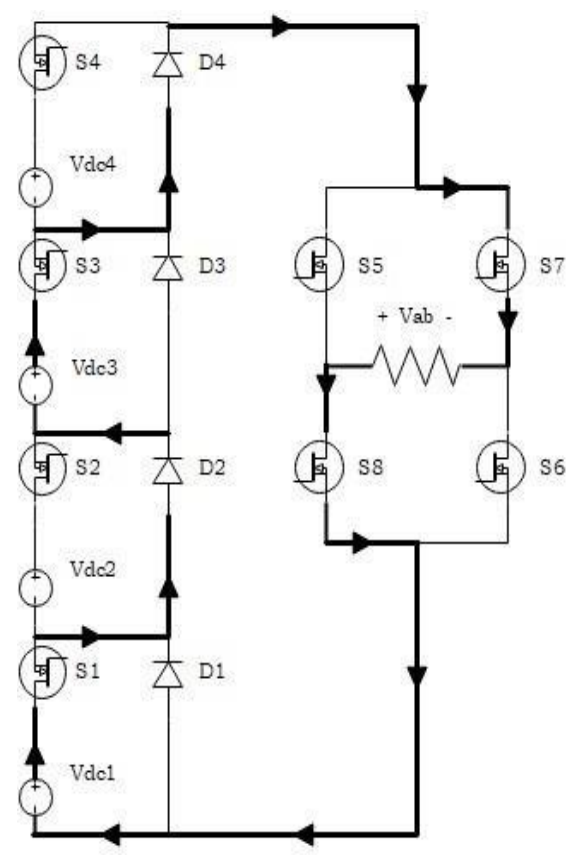

Fig 24. Mode 21
Mode 22:

Switch S2, S3, S7 and S8 is ON, the voltage is $-6 \mathrm{Vdc} / 15$ across the load.

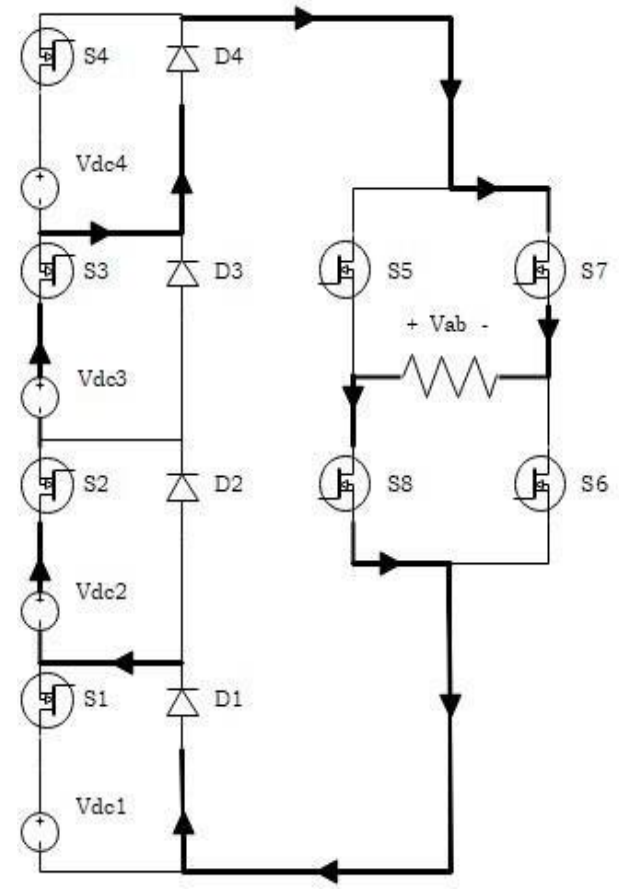

Fig 25. Mode 22

\section{Mode 23:}

Switch S1, S2, S3, S7 and S8 is ON, the voltage is $-7 \mathrm{Vdc} / 15$ across the load.

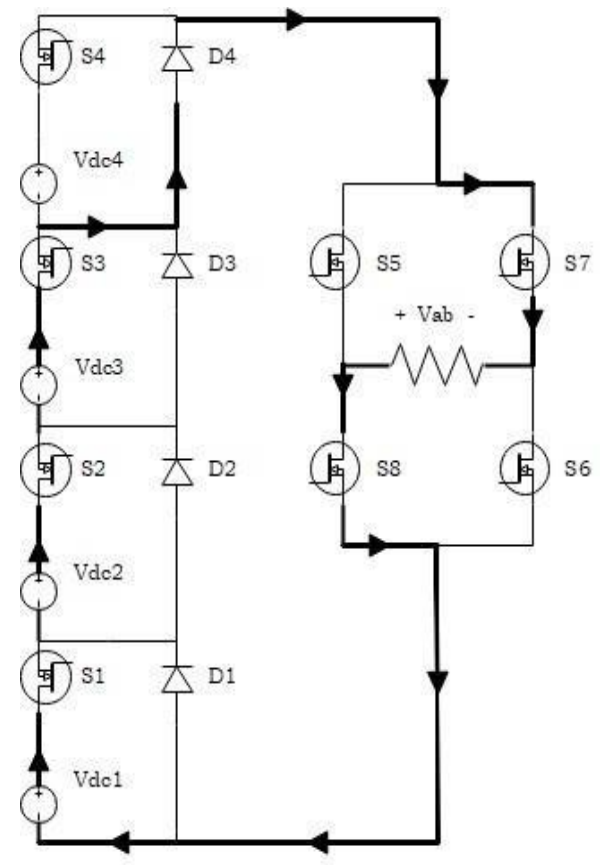

Fig 26. Mode 23 
Vol 2 Iss 2 Year 2020

Mode 24:

Switch S4, S7 and S8 is ON, the voltage is $-8 \mathrm{Vdc} / 15$ across the load.

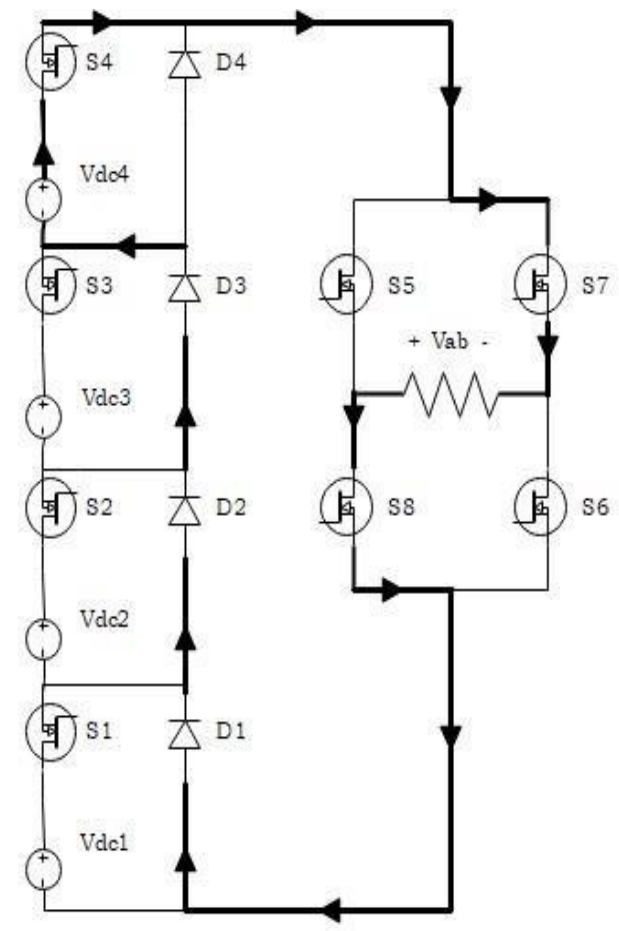

Fig 27. Mode 24

\section{Mode 25:}

Switch S1, S4, S7 and S8 is ON, the voltage is $-9 \mathrm{Vdc} / 15$ across the load.

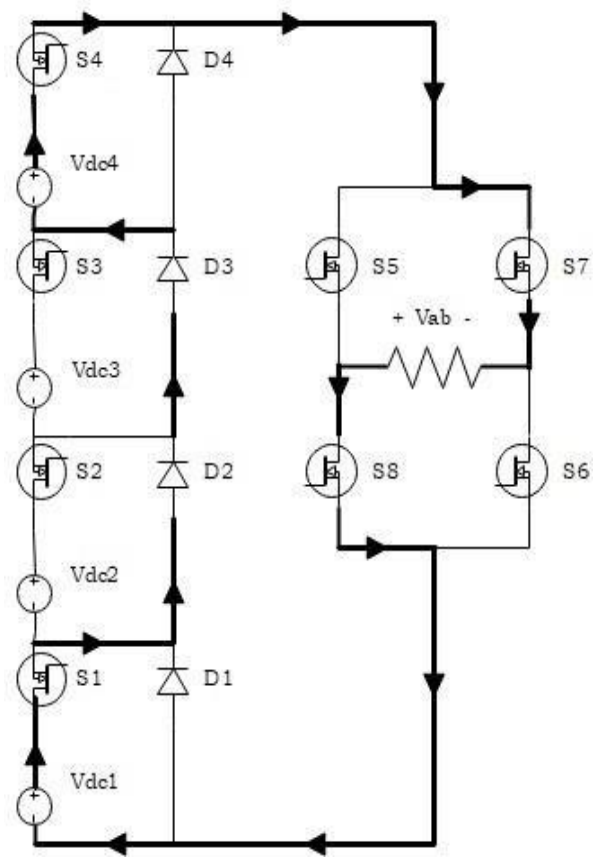

Fig 28. Mode 25
Mode 26:

Switch S2, S4, S7 and S8 is ON, the voltage is $-10 \mathrm{Vdc} / 15$ across the load.

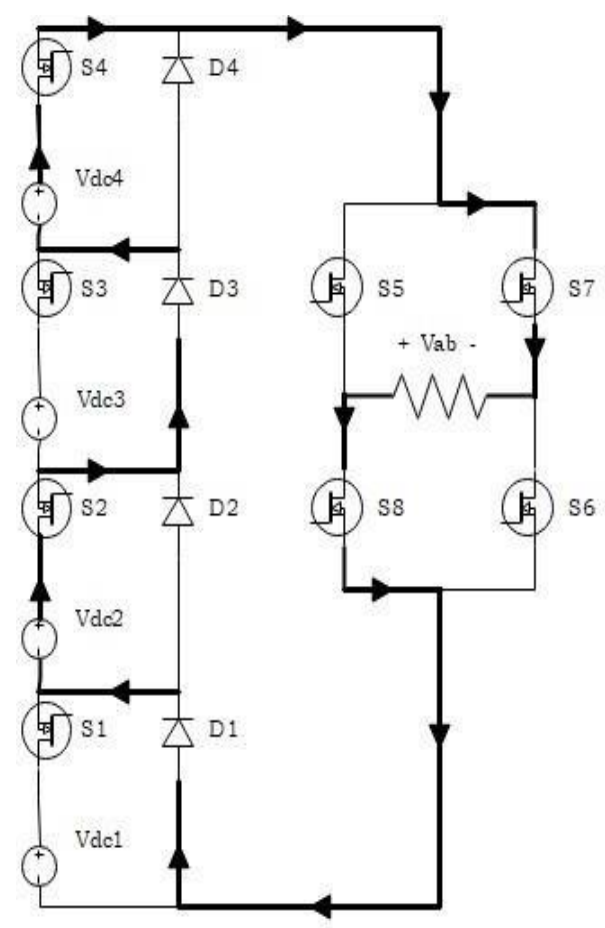

Fig 29. Mode 26

\section{Mode 27:}

Switch S1, S2, S4, S7 and S8 is ON, the voltage is $-11 \mathrm{Vdc} / 15$ across the load.

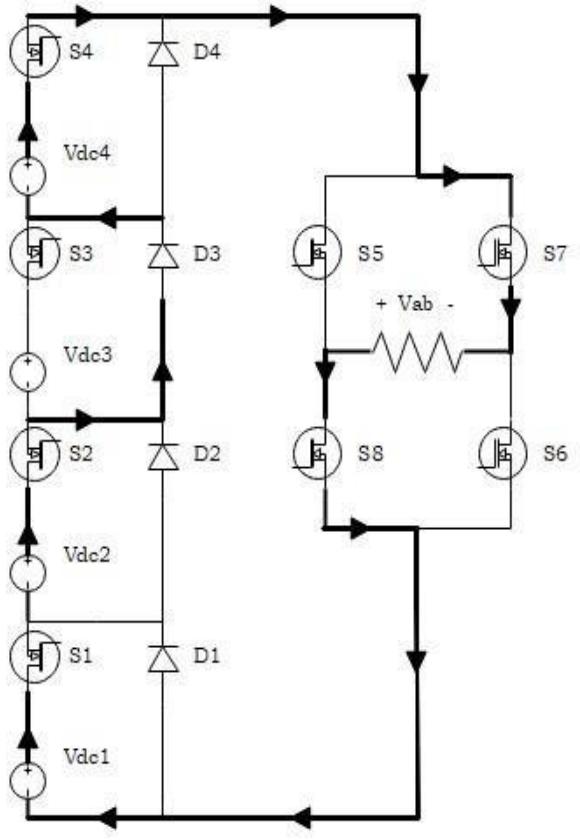

Fig 30. Mode 27 
Vol 2 Iss 2 Year 2020

Mode 28:

Switch S3, S4, S7 and S8 is ON, the voltage is $-12 \mathrm{Vdc} / 15$ across the load.

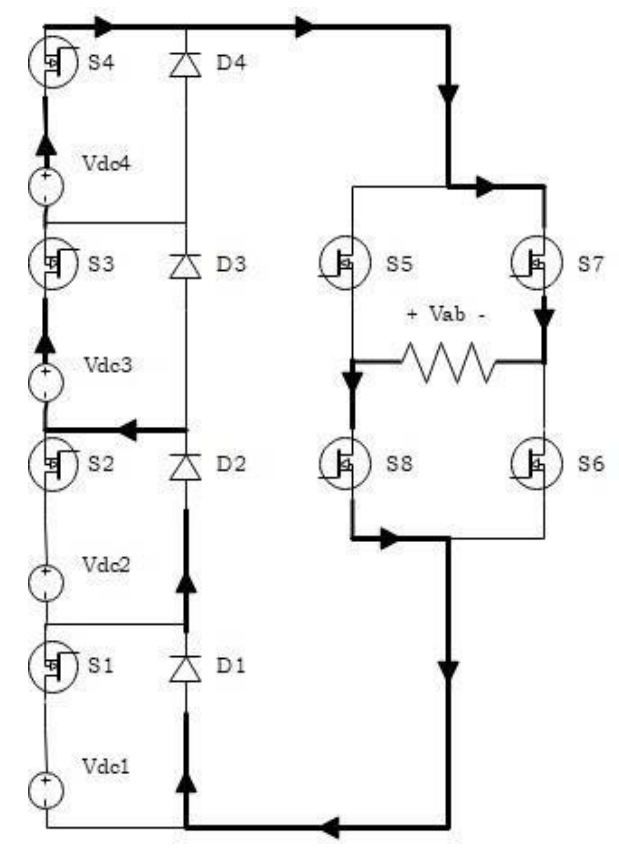

Fig 31. Mode 28

\section{Mode 29:}

Switch S1, S3, S4, S7 and S8 is ON, the voltage is $-13 \mathrm{Vdc} / 15$ across the load.

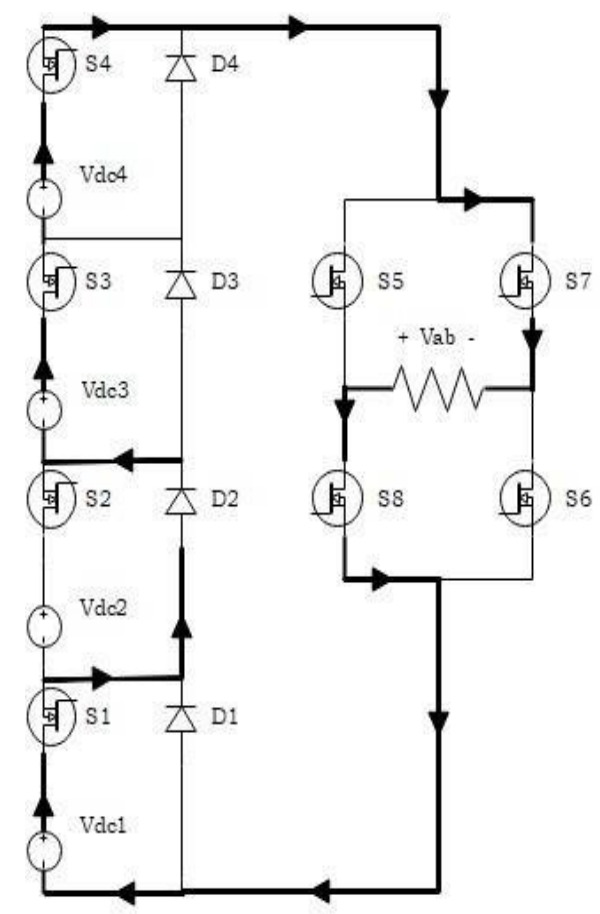

Fig 32. Mode 29
Mode 30:

Switch S2, S3, S4, S7 and S8 is ON, the voltage is $-14 \mathrm{Vdc} / 15$ across the load.

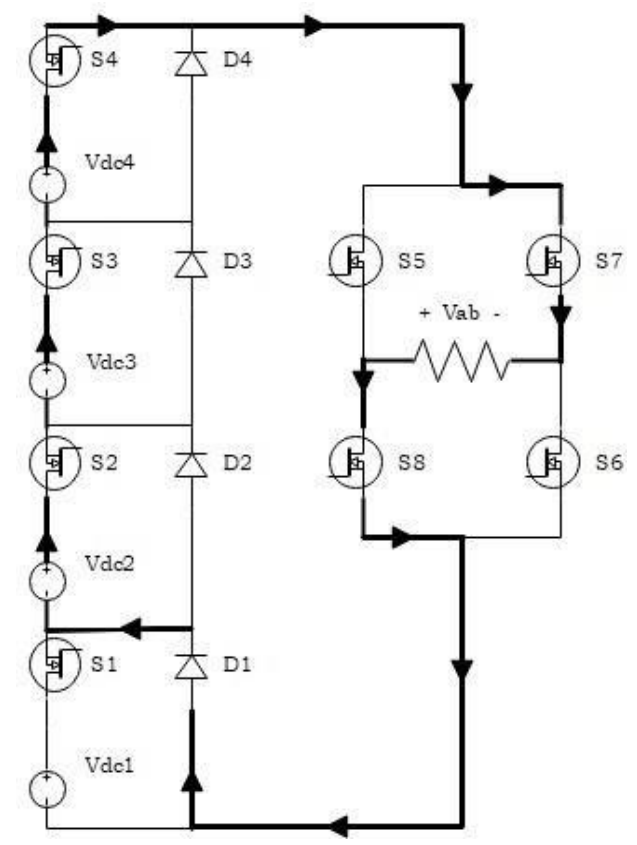

Fig 33. Mode 30

\section{Mode 31:}

Switch S1, S2, S3, S4, S7 and S8 is ON, the voltage is negative maximum $-\mathrm{Vdc}$ across the load.

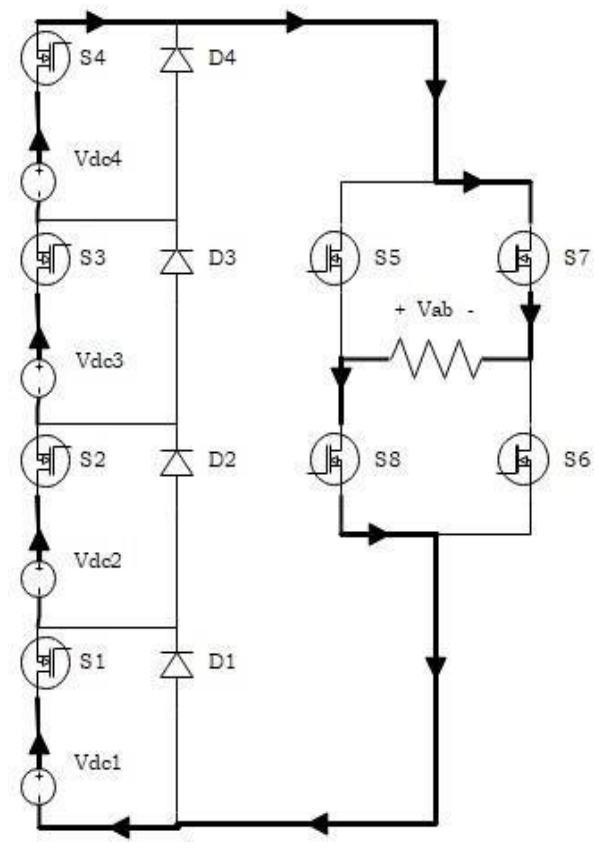

Fig 34. Mode 31 


\section{Modulation Technique}

The pulse width modulation (PWM) uses a fixed DC input voltage which is given to the inverter and produces a controlled AC output voltage by adjusting ON-OFF periods of inverter components which can be exercised as a control for the output voltage within the inverter itself.

\section{Phase Disposition Pulse Width Modulation}

This is a level shifted multiple carrier pulse width modulation technique with all carrier signals in same phase.

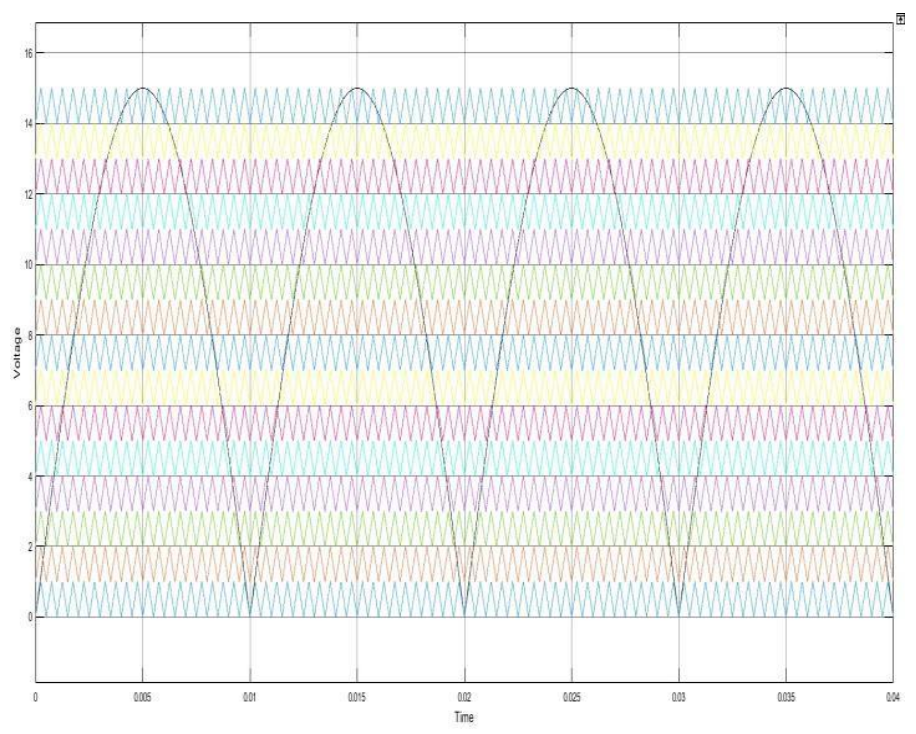

Fig 35. PD-PWM Technique

The reference signal is a sinusoidal wave of frequency $50 \mathrm{~Hz}$ which is compared with triangular carrier waves of frequency $2 \mathrm{Khz}$. The resultant output acts as gate signals for the MOSFETS.

\section{Simulation and Results}

The circuit diagram simulated in MATLAB is shown in Fig. 36.

The PWM control signals are generated in the subsystem block.

The switching pulses given for the switches S1, S2, S3 and S4 respectively is shown in Fig. 38.

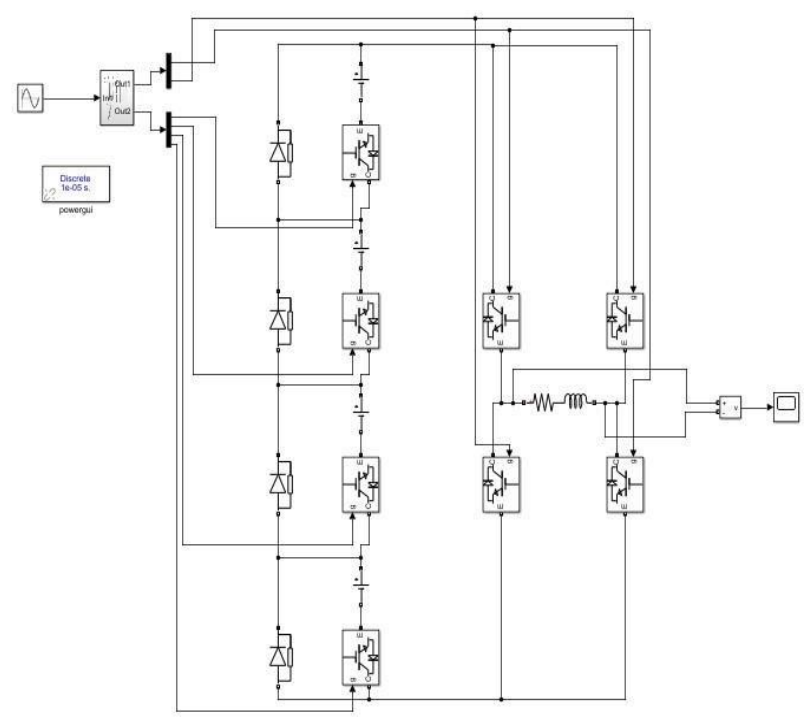

Fig 36. MATLAB Circuit Diagram

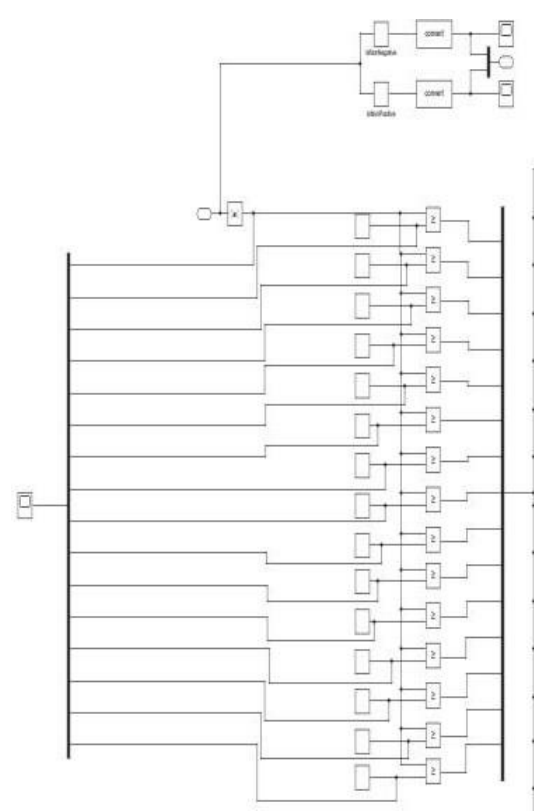

Fig 37. Subsystem Block

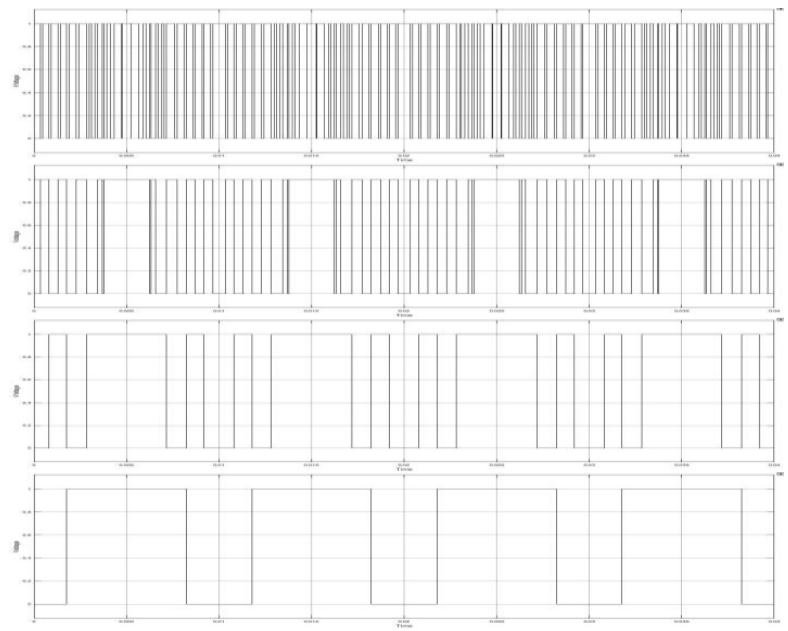

Fig 38. Switching Pulses for S1, S2, S3 and S4 
The switching pulses for H-Bridge is shown in Fig. 39.

The circuit is simulated in MATLAB for different loads like R load of $400 \Omega$ and RL load of $400 \Omega, 20 \mathrm{mH}$. The results obtained for $\mathrm{R}$ anRL load are shown in Fig. 40 and Fig. 41 respectively.

The THD analysis for both the loads are observed and analysed to see the effects of change in loading which are shown in Fig. 42 and Fig. 43.

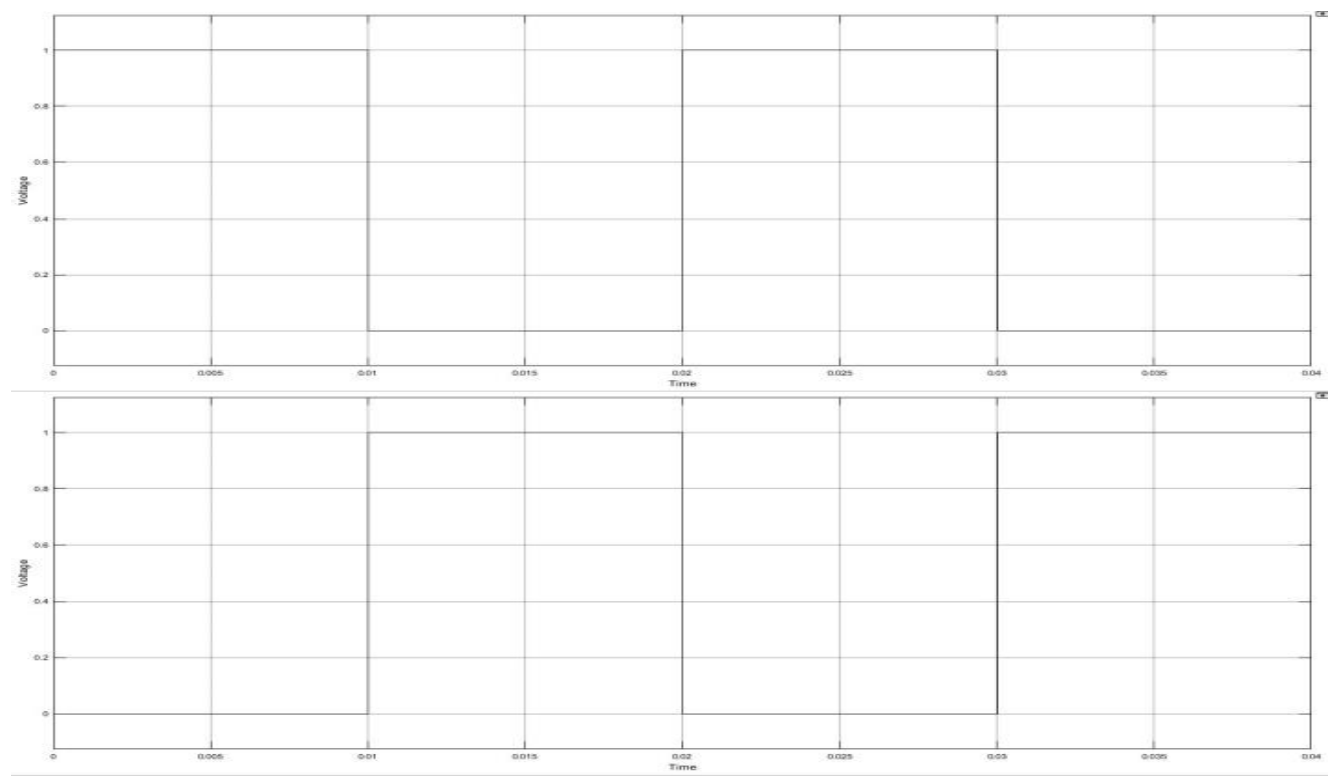

Fig 36. MATLAB Circuit Diagram

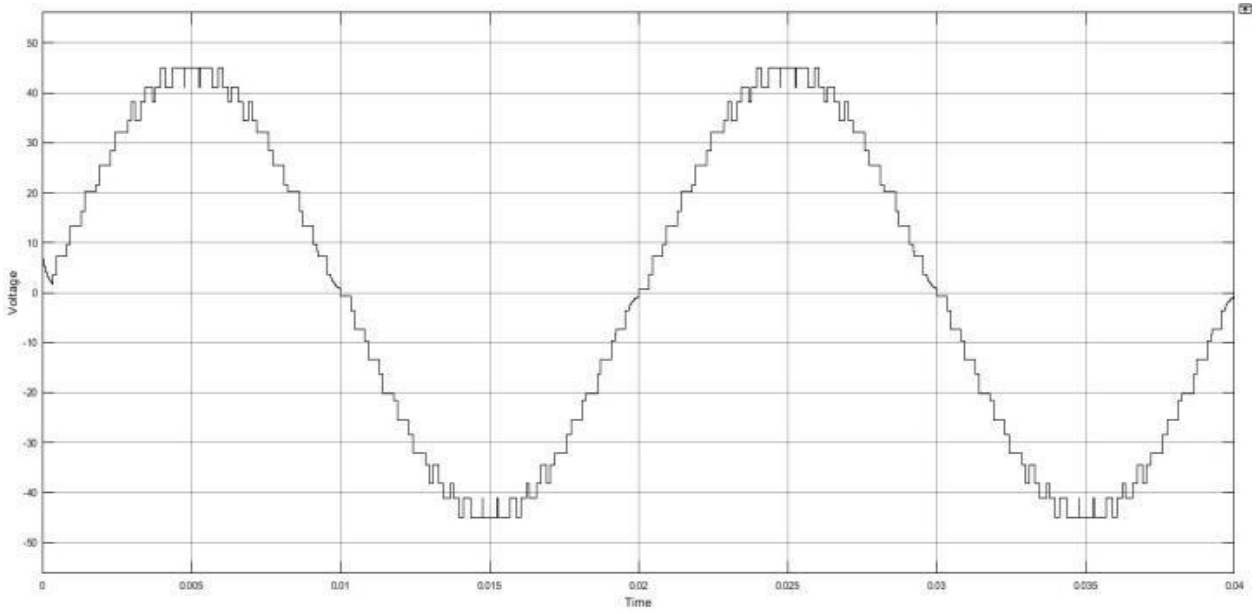

Fig 40. Voltage Waveform for R-Load

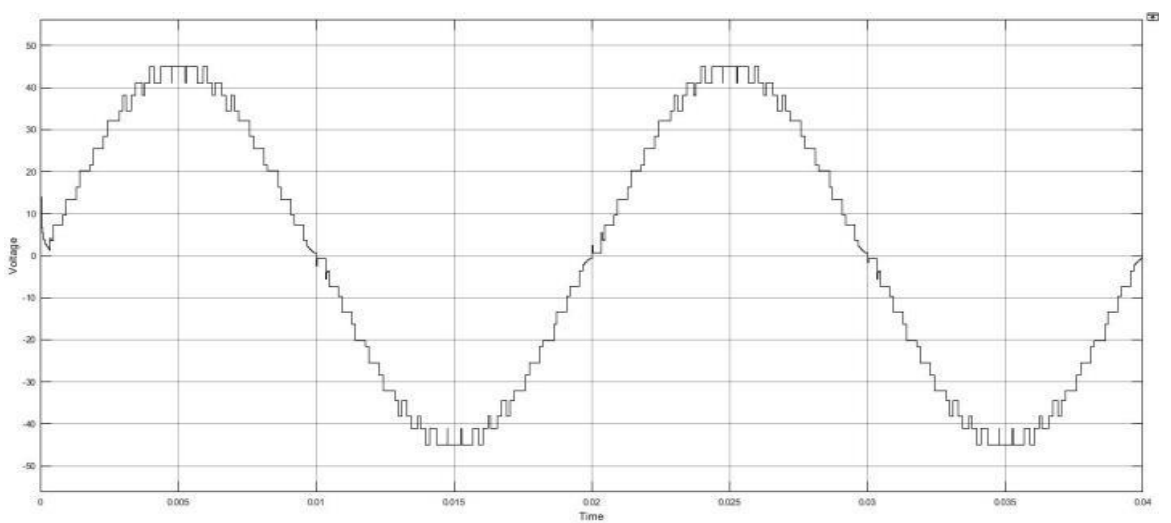

Fig 41. Voltage Waveform for RL-Load 

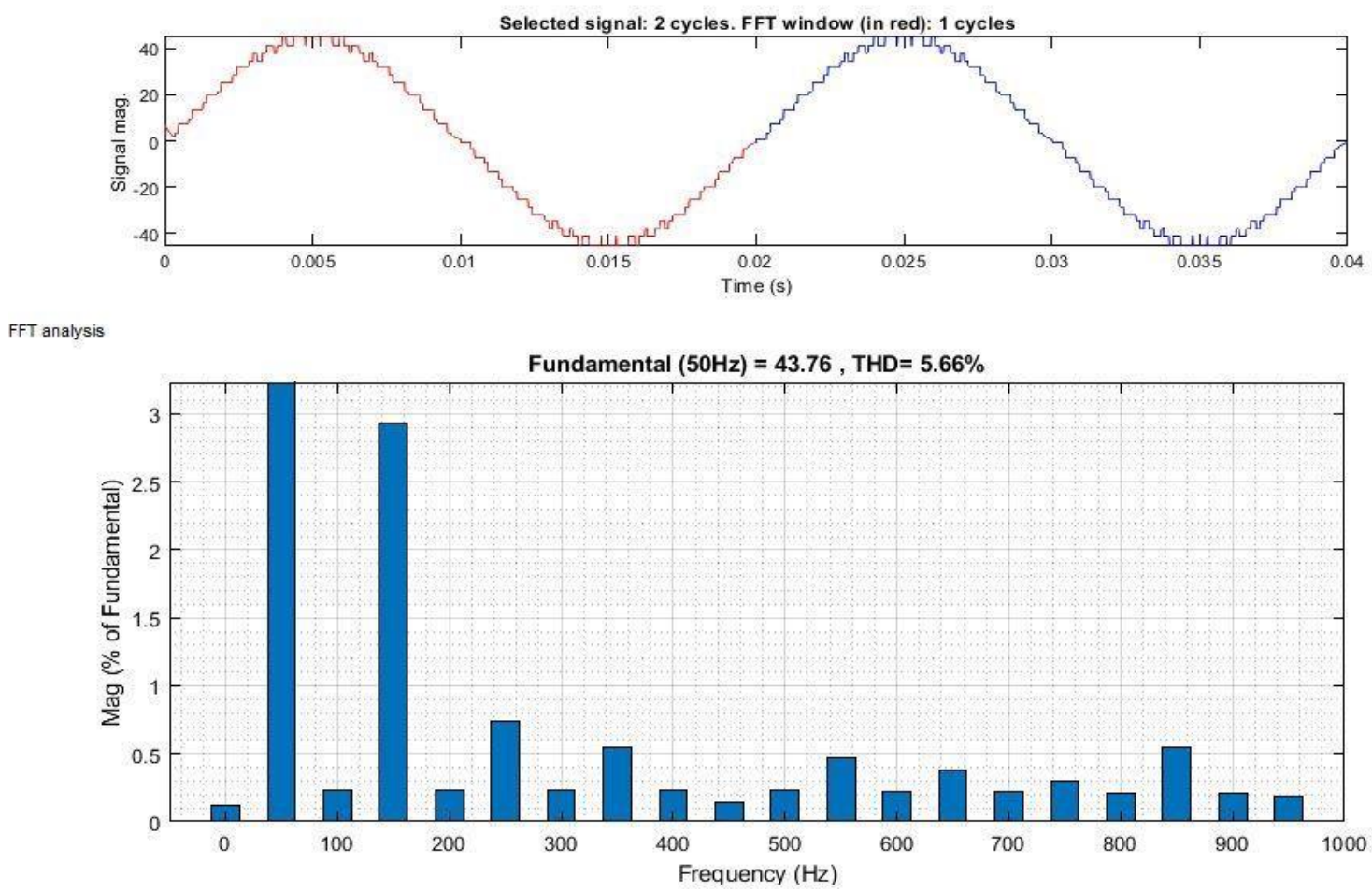

Fig 42. Voltage THD for R-Load

Signal

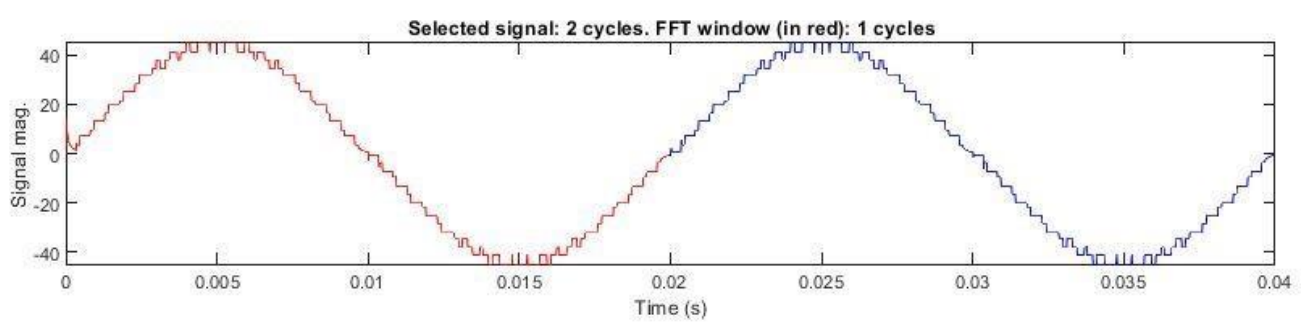

FFT analysis

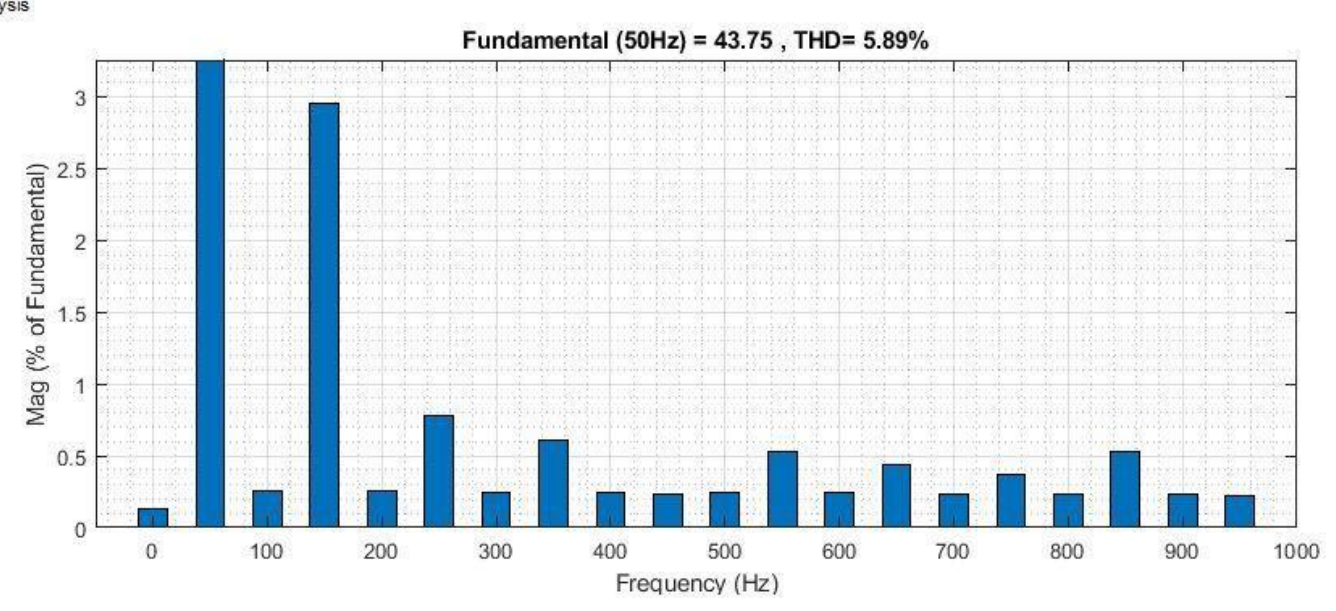

Fig 43. Voltage THD for RL-Load

\section{Conclusion}

The proposed multilevel inverter with reduced number of switches can be implemented for medium and high-power industrial applications. The basic operation of the proposed MLI topology and the generation of required voltage level has been explained. The effective reduction of THD is achieved without using any filter in the circuit. The PDPWM switching technique is simulated in 
MATLAB/SIMULINK for various loads like $\mathrm{R}$ and RL.

\section{References}

[1] M. Q. Abbas, A. Majid, J. Saleem, M. Arif, (2017) Design and Analysis Of 15-Level Asymmetric Multilevel Inverter with Reduced Switch Count Using Different PWM Techniques, In 2017 International Conference on Frontiers of Information Technology (FIT), IEEE, 333-338.

[2] V. Geetha, R. Meenadevi, A 15 Level Multilevel Inverter with Reduced Number of Switches, International Journal of Pure and Applied Mathematics, 119 (2018) 1745-1751.

[3] E. Babaei, S. Alilu, S. Laali, A New General Topology for Cascaded Multilevel Inverters with Reduced Number of Components Based on Developed H-Bridge, IEEE Transactions on Industrial Electronics, 61 (2013) 3932-3939.

[4] T. A. Meynard, M. Fadel, N. Aouda, Modeling of Multilevel Converters, IEEE transactions on industrial electronics, 44 (1997) 356-364.

[5] K. K. Gupta, S. Jain, Topology for Multilevel Inverters to Attain Maximum Number of Levels from Given DC Sources, IET Power Electronics, 5 (2012) 435-446.

[6] C. K. Lee, S. R. Hui, H. S. H. Chung, A 31-Level Cascade Inverter for Power Applications, IEEE Transactions on Industrial Electronics, 49 (2002) 613-617.

[7] E. Babaei, A Cascade Multilevel Converter Topology with Reduced Number of Switches, IEEE Transactions on Power Electronics, 23 (2008) 2657-2664.

[8] C. Dhanamjayulu, G. Arunkumar, B. Jaganatha Pandian, C. V. Ravi Kumar, M. Praveen Kumar, A. Rini Ann Jerin, P. Venugopal, Real-Time Implementation of a 31- Level Asymmetrical Cascaded Multilevel Inverter for Dynamic Loads, IEEE Access, 7 (2019) 51254-51266.

[9] R. S. Alishah, D. Nazarpour, S. H. Hosseini, M. Sabahi, New Hybrid Structure for Multilevel Inverter with Fewer Number of Components for High-Voltage Levels, IET power electronics, 7 (2014) 96-104.

[10] M. D. Siddique, S. Mekhilef, N. M. Shah, A. Sarwar, A. Iqbal, M. A. Memon, A New Multilevel Inverter Topology with Reduce Switch Count, IEEE Access, 7 (2019) 58584-58594.

[11] S. Mukherjee, S. De, S. Sanyal, S. Das, S. Saha, A 15-level asymmetric H-bridge multilevel inverter using d-SPACE with PDPWM technique, International Journal of Engineering, Science and Technology, 11 (2019) 22-32.

[12] T. Rakesh, V. Madhusudhan, M. Sushama, An Exploration of MLI Topology and Control Techniques, International Electrical Engineering Journal (IEEJ), 7 (2016).

[13] J. G. Shankar, J. B. Edward, K. S. Kumar, I. J. Raglend, (2017) A 31-level asymmetrical cascaded multilevel inverter with DC-DC flyback converter for photovoltaic system. In 2017 International Conference on High Voltage Engineering and Power Systems (ICHVEPS), IEEE, 277-282.

[14] M. Gnana Prakash, M. Balamurugan, S. Umashankar, A New Multilevel Inverter with Reduced Number of Switches, International Journal of Power Electronics and Drive System (IJPEDS), 5 (2014) 63.

[15] J. G. Shankar, J. B. Edward, Design and Implementation of 15-Level Asymmetric Cascaded H Bridge Multilevel Inverter, Journal of Electrical Engineering, 17 (2017) 1-9.

[16] S. Rathore, M. K. Kirar, S. K. Bhardwaj, Simulation of cascaded H-bridge multilevel inverter using PD, POD, APOD techniques, Electrical \& Computer Engineering: An International Journal (ECIJ), 4 (2015) 27-41. 
Acknowledgement: NIL

Funding: NIL

Conflict of Interest: NIL

About the License: (C) 2020 The Authors. This work is licensed under a Creative Commons Attribution 4.0 International License which permits unrestricted use, provided the original author and source are credited. 